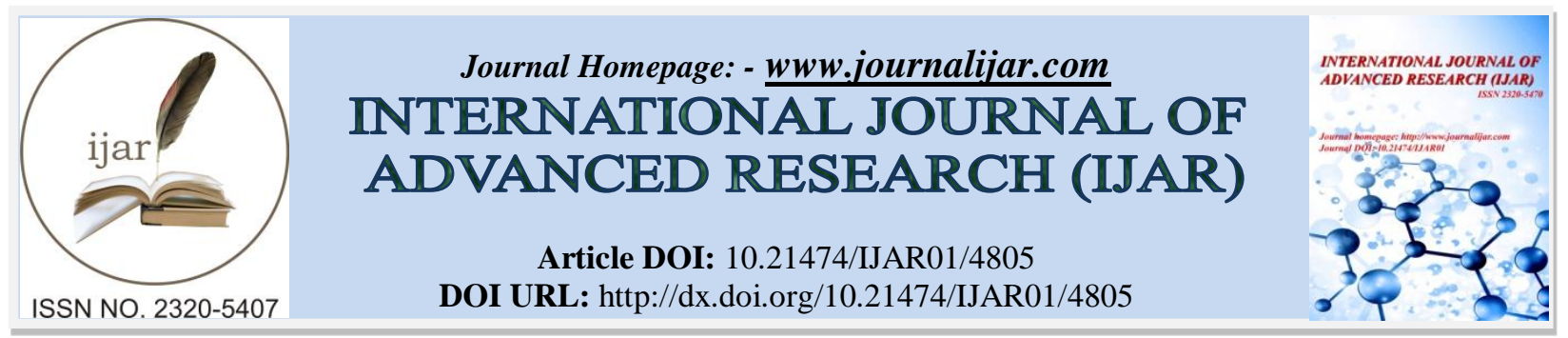

RESEARCH ARTICLE

\title{
STUDY OF COMPARISON BETWEEN AUTONOMIC DYSFUNCTION AND DYSLIPIDEMIA IN HEALTHY POSTMENOPAUSAL WOMEN.
}

Dr. Kavyachand yalamudi.

Consultant physician-khammam.

\section{Manuscript Info}

Manuscript History

Received: 10 May 2017

Final Accepted: 12 June 2017

Published: July 2017

Key words:-

Autonomic dysfunction, dyslipidemia, healthy postmenopausal women

\begin{abstract}
Background: Obesity, physical inactivity, and altered estrogen levels play an important role in contributing to disease risk profile and autonomic dysfunction in healthy postmenopausal women. This study was conducted to test the correlation between autonomic dysfunction and dyslipidemia in healthy postmenopausal women.

Materials and Methods: This study was carried out on sixty healthy postmenopausal women before the age of 65 years, without any gross systemic disease. The following five autonomic functional tests were performed on the study group: heart rate response to deep breathing, heart rate response to Valsalva maneuver, heart rate response to standing up from supine position, blood pressure response to sustained hand grip, and blood pressure response to standing up from supine position. Fasting lipid profile of the study group was tested.

Results and Conclusion: In the present study, autonomic dysfunction was found in $67 \%$ of healthy postmenopausal women. Among the sixty female healthy postmenopausal women included in the study, 68\% were found to have dyslipidemia. In our study, there is a statistically significant correlation between autonomic dysfunction and dyslipidemia in healthy postmenopausal women. In these healthy postmenopausal women with increased serum cholesterol, serum lowdensity lipoprotein, and serum triglycerides, there was autonomic dysfunction which is statistically significant. There is no statistical significance on comparing serum high-density lipoprotein cholesterol with autonomic dysfunction in healthy postmenopausal women.
\end{abstract}

Copy Right, IJAR, 2017,. All rights reserved.

\section{Introduction:-}

Menopause is the permanent cessation of menstruation due to the loss of ovarian function which occurs at a mean age of 50 years.[1]

The ovaries no longer secrete progesterone and estrogen in appreciable quantities. The transition from premenopause to postmenopause is associated with many features of metabolic syndrome.[2]

The emergence of risk factors may be a direct result of ovarian failure or an indirect result of metabolic consequences or central fat redistribution with estrogen deficiency.[3] 
The hormonal changes associated with menopause, that is, low plasma levels of estrogen and marked increase in follicle-stimulating hormone and luteinizing hormonexert a significant effect on plasma lipids and lipoproteins leading to increase in low-density lipoprotein (LDL) cholesterol and decrease in high-density lipoprotein (HDL) cholesterol, henceforth, leading to increased risk of cardiovascular disease in postmenopausal women. [4]

Decreased level of estrogen in postmenopausal women causes alteration in cardiac autonomic system leading to a decrease in vagal tonic modulation of the heart rate in the setting of preserved sympathetic tone and consequently there is predominance of sympathetic tone leading to decreased heart rate variability further predisposing to cardiovascular disease in the postmenopausal women.[4-6]

Various research evidences suggest that cardiovascular autonomic balances are related to baroreceptor sensitivity and heart rate variability. It has been observed that in women, oophorectomy suppresses baroreceptor sensitivity and heart rate variability.[3] It has also been demonstrated that estrogen supplementation increases baroreceptor sensitivity and heart rate variability.[3]

Various studies suggested beneficial effect of estrogen replacement therapy would reduce the relative risk for cardiovascular mortality, due to actions of estrogen on improving serum cholesterol profile by decreasing total cholesterol (TC) and LDL cholesterol and increasing HDL cholesterol. Estrogen was considered beneficial by relaxing smooth muscles, endothelium-dependent vasodilation formation, and decreasing fibrinogen levels causing favorable impact on clotting mechanism along with direct inotropic effect on heart.[6]

During postmenopausal period, due to hormonal imbalance, a myriad of vague symptoms centered around vasomotor symptoms arise such as hot flushes and sweating, and emotional symptoms such as depression and anxiety may occur in symptomatic postmenopausal women.[6]

Various studies have shown that in healthy postmenopausal women, dyslipidemia is associated with heart rate variability, as a result of decreased level of estrogen.

\section{Materials and Methods:-}

\section{Materials:-}

The present study titled "STUDY OF COMPARISION BETWEEN AUTONOMIC DYSFUNCTION AND DYSLIPIDEMIA IN HEALTHY POSTMENOPAUSAL WOMEN" was carried out on sixty healthy postmenopausal women before the age of 65 years, in medicine wards of Padmashree Dr. D. Y. Patil Hospital from July 2012 to July 2014. The Institute Ethics Committee clearance was obtained before the start of study. All patients were explained about the nature of the study and informed consent was obtained from all the patients.

\section{Inclusion criteria:-}

All healthy postmenopausal women who have attained menopause by natural means before the age of 65 years.

\section{Exclusion criteria:-}

Postmenopausal women with:

a. Diabetes mellitus

b. Hypertension

c. Obesity

d. Underwent hysterectomy/oophorectomy

e. On hormone replacement therapy

f. On lipid-lowering drugs

g. History of hormonal imbalance or hormonal disorder.

Methods and study plan:-

A total number of sixty postmenopausal women admitted in medicine wards of Dr. D. Y. Patil Hospital and Research Centre, Pimpri, Pune, were evaluated by taking a detailed clinical history and clinical examination.

Clinical examination was done:

Detailed neurological examination was done to detect autonomic dysfunction by five standard bedside cardiovascular tests. 
The five autonomic dysfunction tests were explained in detail in the review of literature of this present study.

1. Heart rate response to Valsalva maneuver - The Valsalva ratio, that is, the ratio of longest $R$ R interval after 20 beats of end of maneuver to the shortest $\mathrm{R} R$ interval during the maneuver was calculated. The result was taken as three successive readings. A ratio of 1.1 or lower was taken abnormal[7-10] [Figure 1]

2. Heart rate response to Valsalva maneuver - The Valsalva ratio, that is, the ratio of longest R-R interval after 20 beats of end of maneuver to the shortest R-R interval during the maneuver was calculated. The result was taken as three successive readings. A ratio of 1.1 or lower was taken abnormal[7-10]

3. Heart rate response to standing up from supine position - The ratio of longest R-R interval around 30th beat after standing. To the shortest $\mathrm{R}-\mathrm{R}$ interval, around 15 th beat after standing was calculated. A ratio $<1$ was taken as abnormal[7-10].

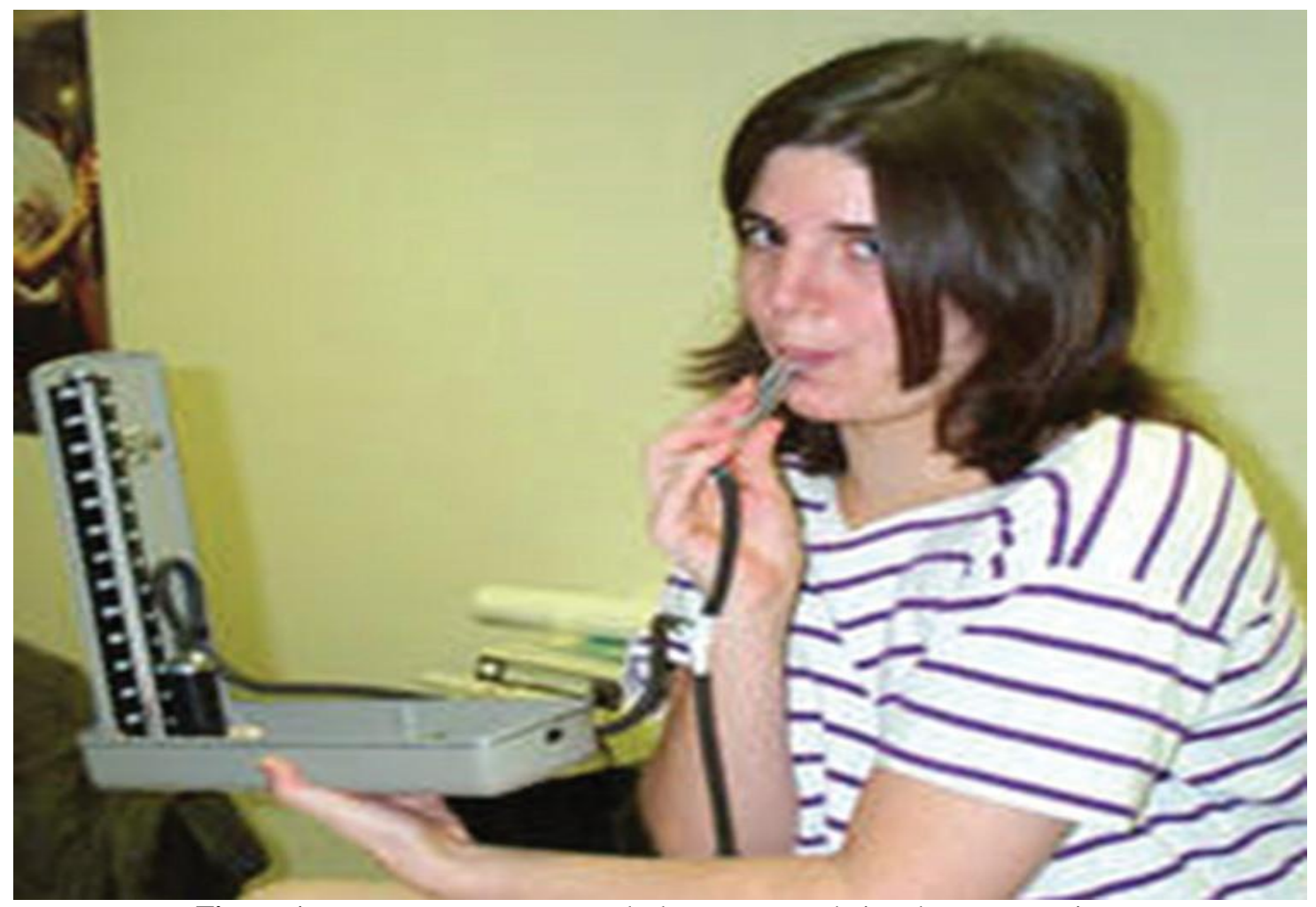

Figure 1:-Heartrate response to valsalva maneuver being done on a patient

4. Blood pressure response to sustained handgrip - $\mathrm{A}<10 \mathrm{mmHg}$ increase in diastolic pressure before and $3 \mathrm{~min}$ after sustained handgrip was taken as abnormal[7-10]

5. Blood pressure response to standing up from supine position - It was measured while the participant was lying supine and again $1 \mathrm{~min}$ after standing up and the difference was noted. In normal participant, the systolic blood pressure should not decrease by more than $10 \mathrm{mmHg}$, in patients with autonomic dysfunction, the systolic blood pressure falls more than $30 \mathrm{mmHg}$ [7-10] [Figure 2]. 


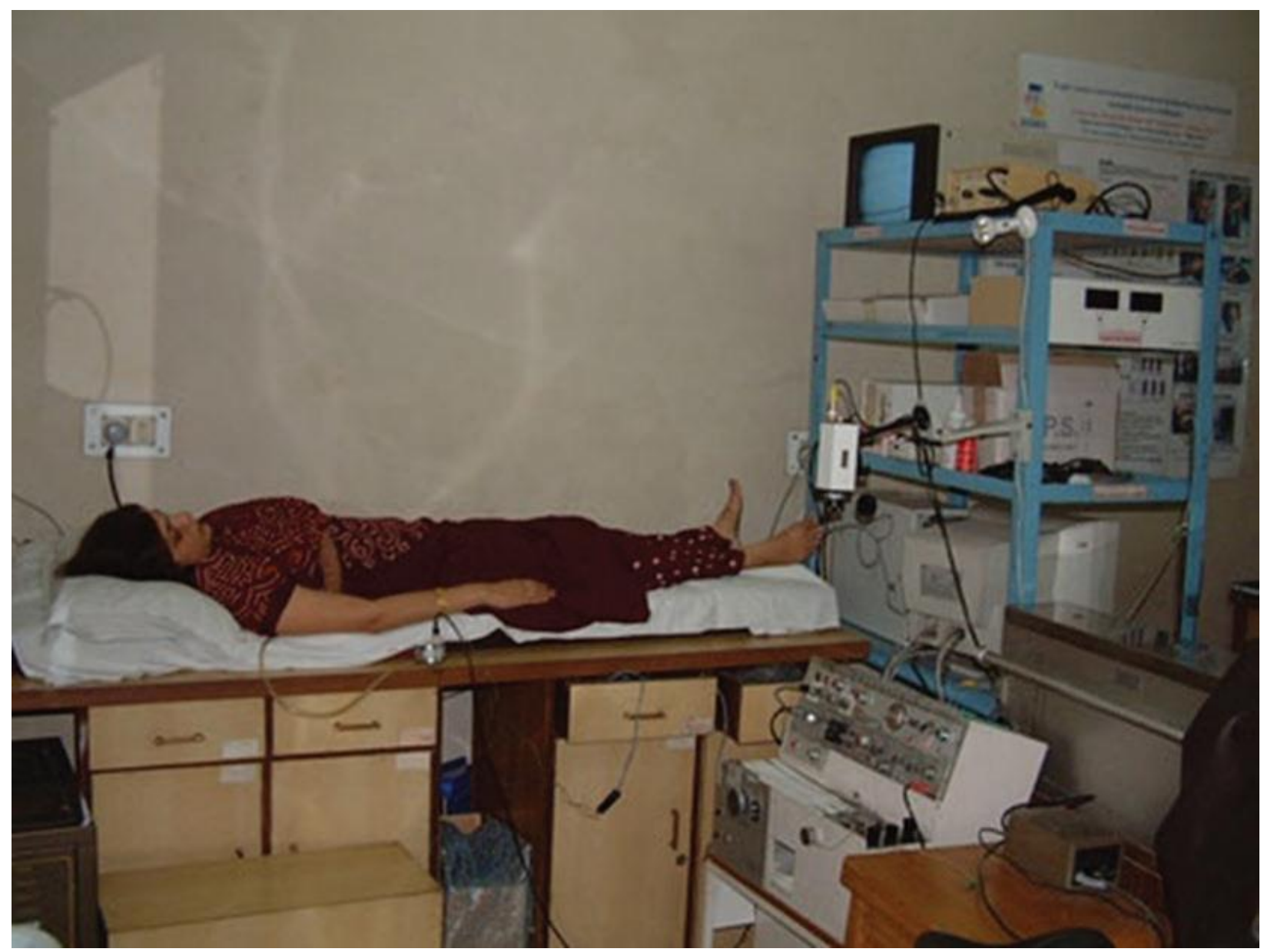

Figure 2:-Blood pressure response to standing up from supine position

Autonomic dysfunction when present will be classified using criteria of Ewing and Clarke as follows:

1. Normal: All five tests normal

2. Early involvement: One of the three heart rate tests abnormal

3. Definite involvement: Two or more of the heart rate tests abnormal

4. Severe involvement: Two or more of the heart rate tests abnormal plus one or both of the blood pressure tests abnormal

5. Atypical pattern: Any other combination of abnormal tests.

\section{Investigations:-}

All patients who fulfilled inclusion criteria underwent investigations. Blood was withdrawn from all patients for hemoglobin, fasting lipid profile, and fasting blood sugar. All patients underwent ECG to look for evidence of ischemic heart disease.

\section{Fasting lipid profile:-}

A volume of $10 \mathrm{ml}$ of blood after $12 \mathrm{~h}$ of fasting was collected for the analysis of lipid profile. The analysis was performed on autoanalyzer ERBA SmartLab ERBA test kit REKT104 for TC, REKT40 for triglycerides (TGLs), and REKT106 for HDL, LDL cholesterol was calculated using the Freidewald formula:

LDL cholesterol $=$ TC - HDL cholesterol - TGLs $/ 5$.

The levels of the individual fractions of the lipid profile were interpreted as follows, in accordance with the National Cholesterol Education Program guidelines[11] [Table A]. 
Table A:-The levels of the individual fractions of the lipid profile as per NCEP

\begin{tabular}{|l|l|}
\hline Normal values & Level $(\mathbf{m g} / \mathbf{d l})$ \\
\hline Total cholesterol & $<200$ \\
\hline Desirable & $200-239$ \\
\hline Borderline high & $\geq 240$ \\
\hline High & $<130$ \\
\hline LDL cholesterol & $130-159$ \\
\hline Desirable & $>160$ \\
\hline Borderline high & $>60$ \\
\hline High & $40-60$ \\
\hline HDL cholesterol & $<40$ \\
\hline Desirable & $<150$ \\
\hline Borderline low & $150-199$ \\
\hline Low & $\geq 200$ \\
\hline Triglycerides & \multicolumn{2}{|l|}{} \\
\hline Desirable & \\
\hline Borderline high & \\
\hline High & \\
\hline HDL: High-density lipoprotein, LDL: Low-density lipoprotein \\
\hline
\end{tabular}

\section{Results:-}

Of the sixty healthy postmenopausal women included in the study group, 67\% had autonomic dysfunction and 33\% did not have autonomic dysfunction. This distribution is seen in the pie diagram [Figure 3 and Table 1].

\section{Pie diagram showing autonomic dysfunction-wise distribution of cases in study group}

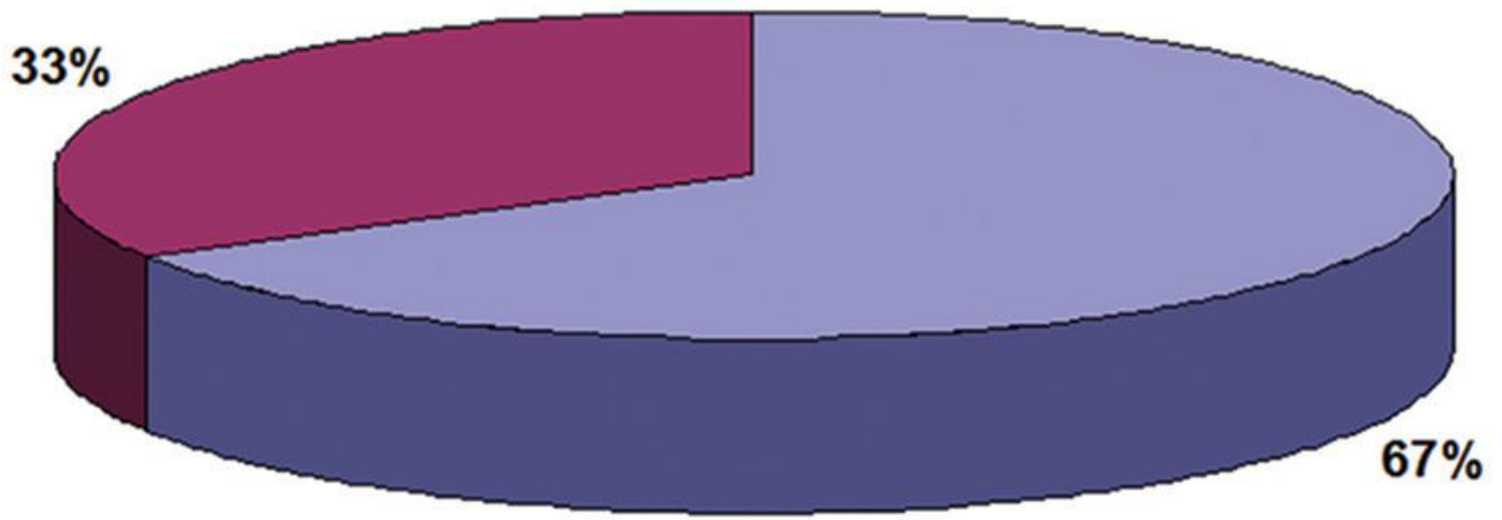

\section{Present $\square$ Absent}

Figure 3:-Pie diagram showing Autonomic dysfunction-wise distribution of cases in study group

Table1:- Autonomic dysfunction wise distribution of cases in study group

\begin{tabular}{|l|l|l|}
\hline Autonomic dysfunction & No of cases & Percentage \\
\hline Present & 40 & 66.67 \\
\hline Absent & 20 & 33.33 \\
\hline Total & 60 & 100 \\
\hline
\end{tabular}


-Of the sixty healthy postmenopausal women included in the study, $68 \%$ had dyslipidemia and $33 \%$ did not have dyslipidemia. This distribution is seen in the pie diagram [Figure 4 and Table 2].

\section{Pie diagram showing dyslipidemia-wise distribution of cases in study group}

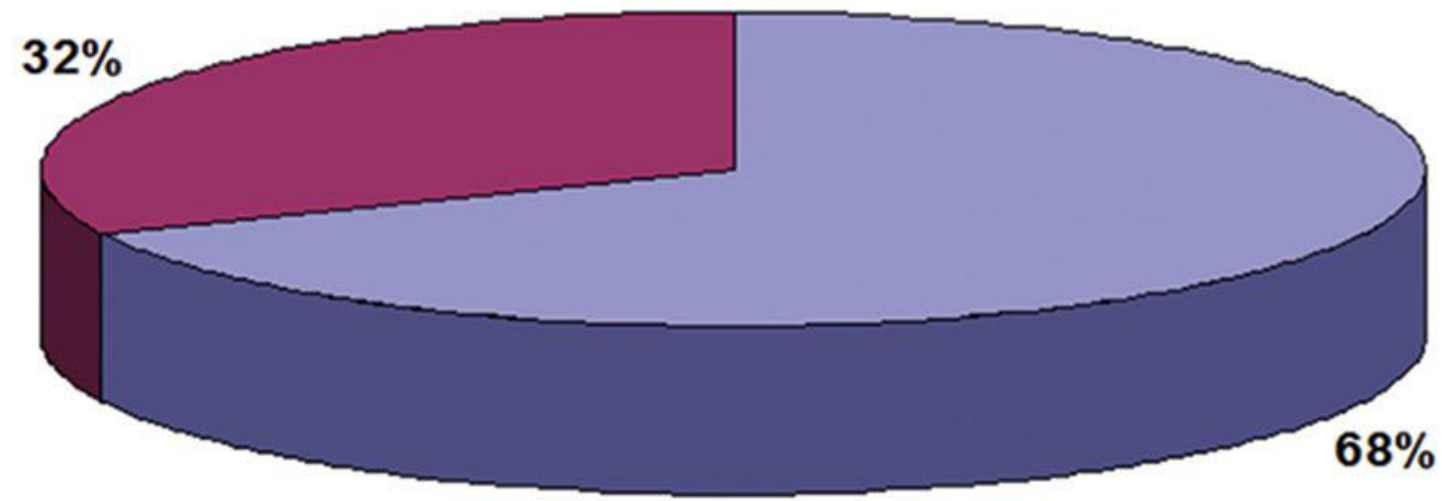

\section{$\square$ Present $\square$ Absent}

Figure 4:-Pie diagram showing dyslipidemia-wise distribution of cases in study group

Table 2:-Dyslipidemia wise distribution of cases in study group

\begin{tabular}{|l|l|l|}
\hline Dyslipidemia & No of cases & Percentage \\
\hline Present & 41 & 68.33 \\
\hline Absent & 19 & 31.67 \\
\hline Total & 60 & 100 \\
\hline
\end{tabular}

-Out of sixty healthy postmenopausal women, 41 patients have dyslipidemia - out of which 40 patients have autonomic dysfunction. The $P<0.0001$ is statistically significant hence proving a strong correlation between dyslipidemia and autonomic dysfunction in healthy postmenopausal women. This distribution is seen in the bar diagram [Figure 5 and Table 3]. 


\section{Bar diagram showing association between Dyslipidemia and Autonomic dysfunction in study group}

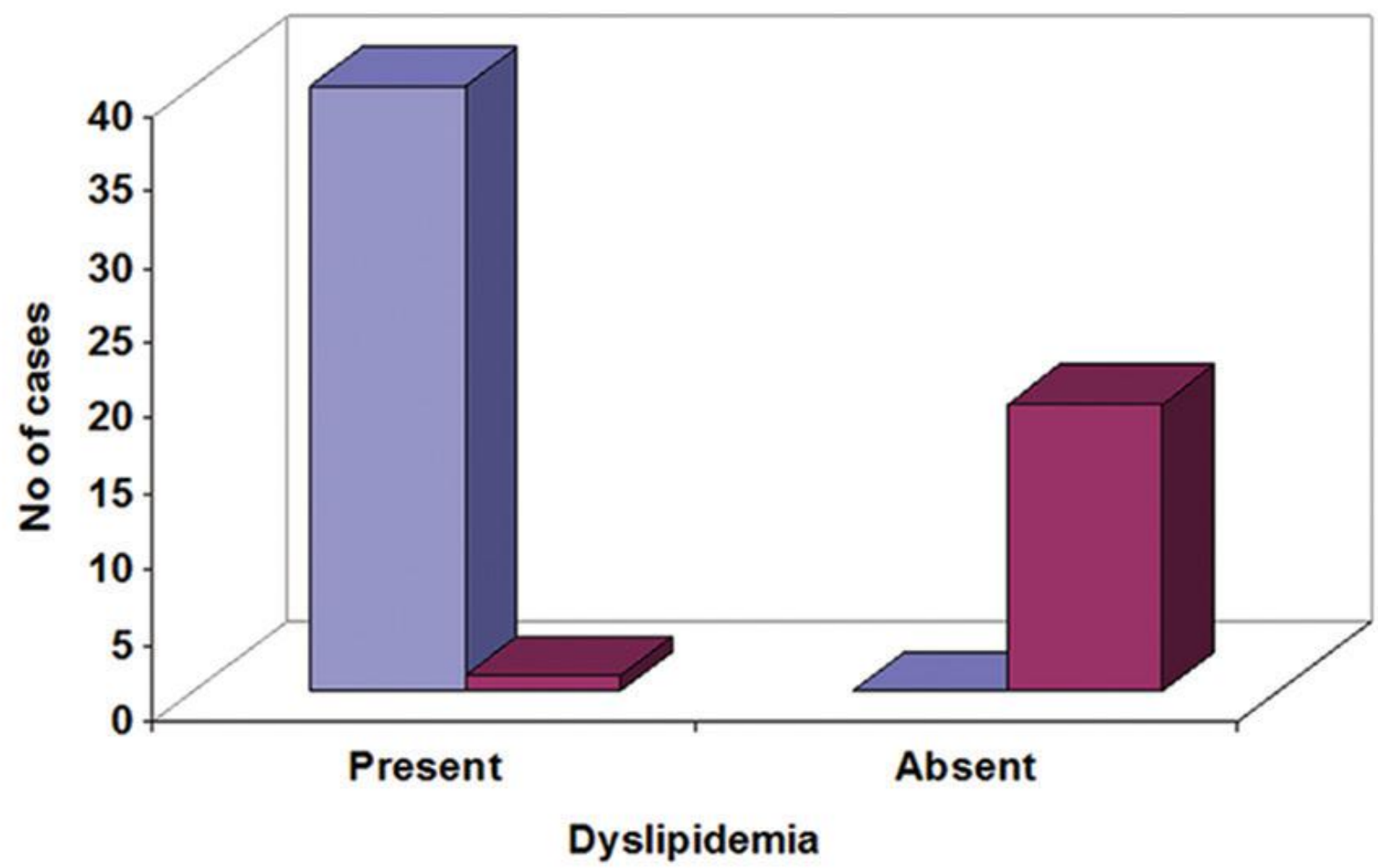

\section{Autonomic dysfunction Present $\square$ Autonomic dysfunction Absent}

Figure 5:-Bar diagram showing association between autonomic dysfunction and dyslipidemia in study group

Table 3:-Association between Dyslipidemia and Autonomic dysfunction in study group

\begin{tabular}{|ll|l|l|l|}
\hline \multirow{2}{*}{ Dyslipidemia } & \multicolumn{2}{|l|}{ Autonomic dysfunction } & \multirow{2}{*}{ Total } \\
\cline { 2 - 5 } & Present & Absent & \\
\hline Present - & $\mathbf{4 1}$ & 40 & 1 & 41 \\
\hline Absent - & $\mathbf{1 9}$ & 0 & 19 & 19 \\
\hline \multicolumn{2}{|l|}{60} & 40 & 20 & 60 \\
\hline Sensitivity $=100 \%$ & Specificity $=95 \% \quad$ PPV $=97.56 \% \quad$ NPV $=100 \%$
\end{tabular}

-In this study, the cutoff value for normal TC is taken as dysfunction, $P<0.0001$ which is statistically significant. Hence, the correlation of autonomic dysfunction and serum cholesterol level in healthy postmenopausal women is proved [Figure 6 and Table 4].

Table 4:-Comparison of Sr. Cholesterol according to autonomic dysfunction in study group

\begin{tabular}{|l|l|l|l|l|l|l|}
\hline \multirow{2}{*}{ Parameter } & \multicolumn{2}{|l|}{ Autonomic dysfunction } & \multirow{2}{*}{ Z Value } & \multirow{2}{*}{ P Value } \\
\cline { 2 - 5 } & Present (n=40) & \multicolumn{2}{|l|}{ Absent (n=20) } & \\
\cline { 2 - 5 } & Mean & SD & Mean & SD & & \\
\hline Sr. Chol. (mg\%) & 211.8 & 14.3 & 151.2 & 30.7 & 8.40 & $<0.0001$ \\
\hline
\end{tabular}




\section{Bar diagram showing comparison of Sr. cholesterol according to autonomic dysfunction in study group}

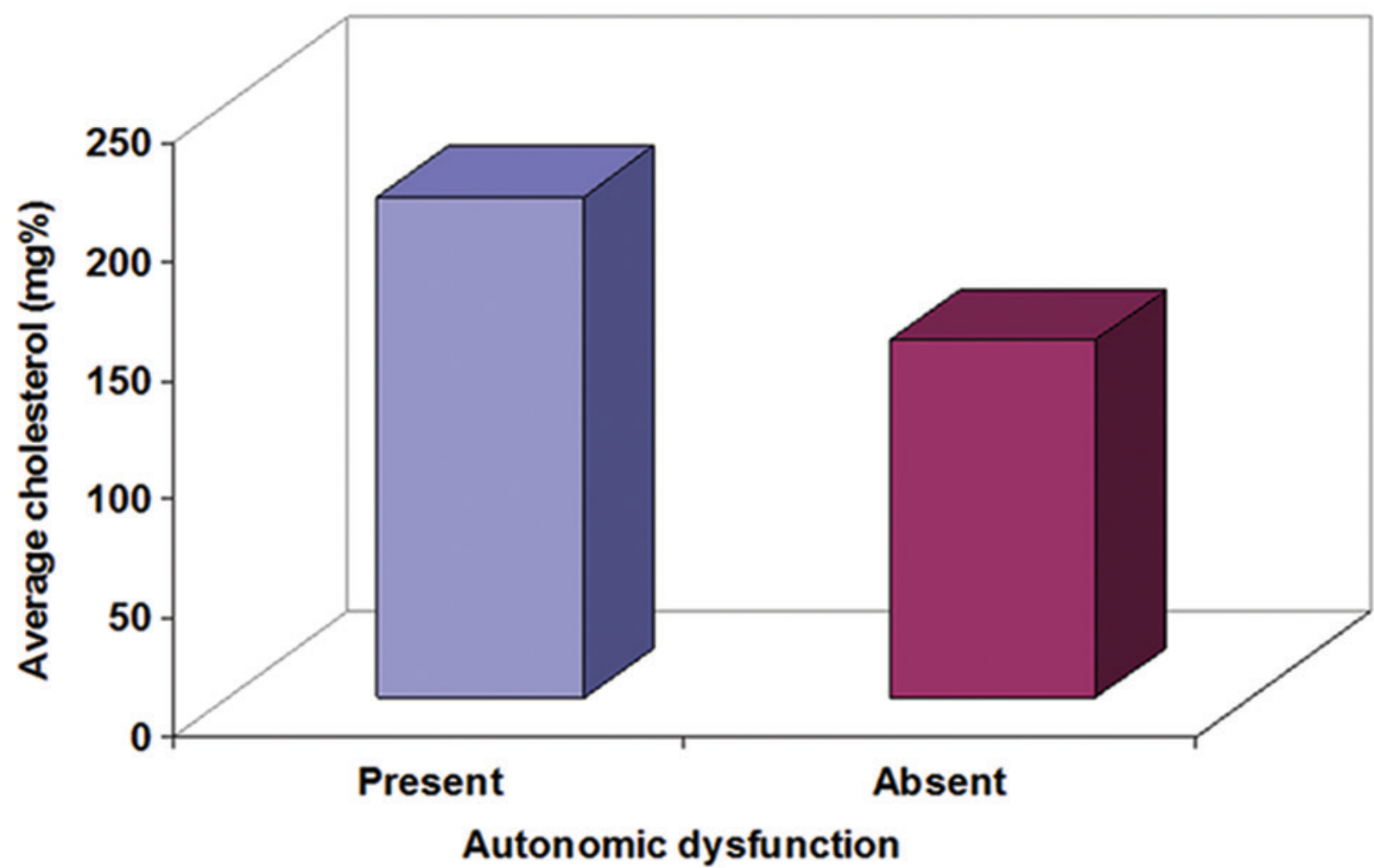

Figure 6:-Bar diagram showing comparision of serum cholesterol according to autonomic dysfunction in study group

-In the study,The cut off value for normal total Triglyceride is taken as $<150 \mathrm{mg} / \mathrm{dl}$ and on comparision with autonomic dysfunction, $\mathrm{p}$ value $<0.0001$ which is statistically significant.Hence the correlation of autonomic dysfunction and serum triglyceride level in healthy postmenopausal women is proved[Figure 7 and Table 5]

Table 5:-Comparison of Sr. Triglyceride according to autonomic dysfunction in study group

\begin{tabular}{|l|l|l|l|l|l|l|}
\hline \multirow{3}{*}{ Parameter } & \multicolumn{2}{|l|}{ Autonomic dysfunction } & \multirow{2}{*}{ Z Value } & \multirow{2}{*}{ P Value } \\
\cline { 2 - 5 } & Present (n=40) & \multicolumn{2}{|l|}{ Absent $(\mathbf{n = 2 0})$} & \\
\cline { 2 - 4 } & Mean & SD & Mean & SD & & \\
\hline Sr. Tg. (mg\%) & 177.5 & 20.3 & 107.8 & 20.5 & 12.46 & $<0.0001$ \\
\hline
\end{tabular}


Figure 7:-Bar diagram showing comparision of serum triglycerides according to autonomic dysfunction in study group

\section{Bar diagram showing comparison of Sr. Triglyceride according to autonomic dysfunction in study group}

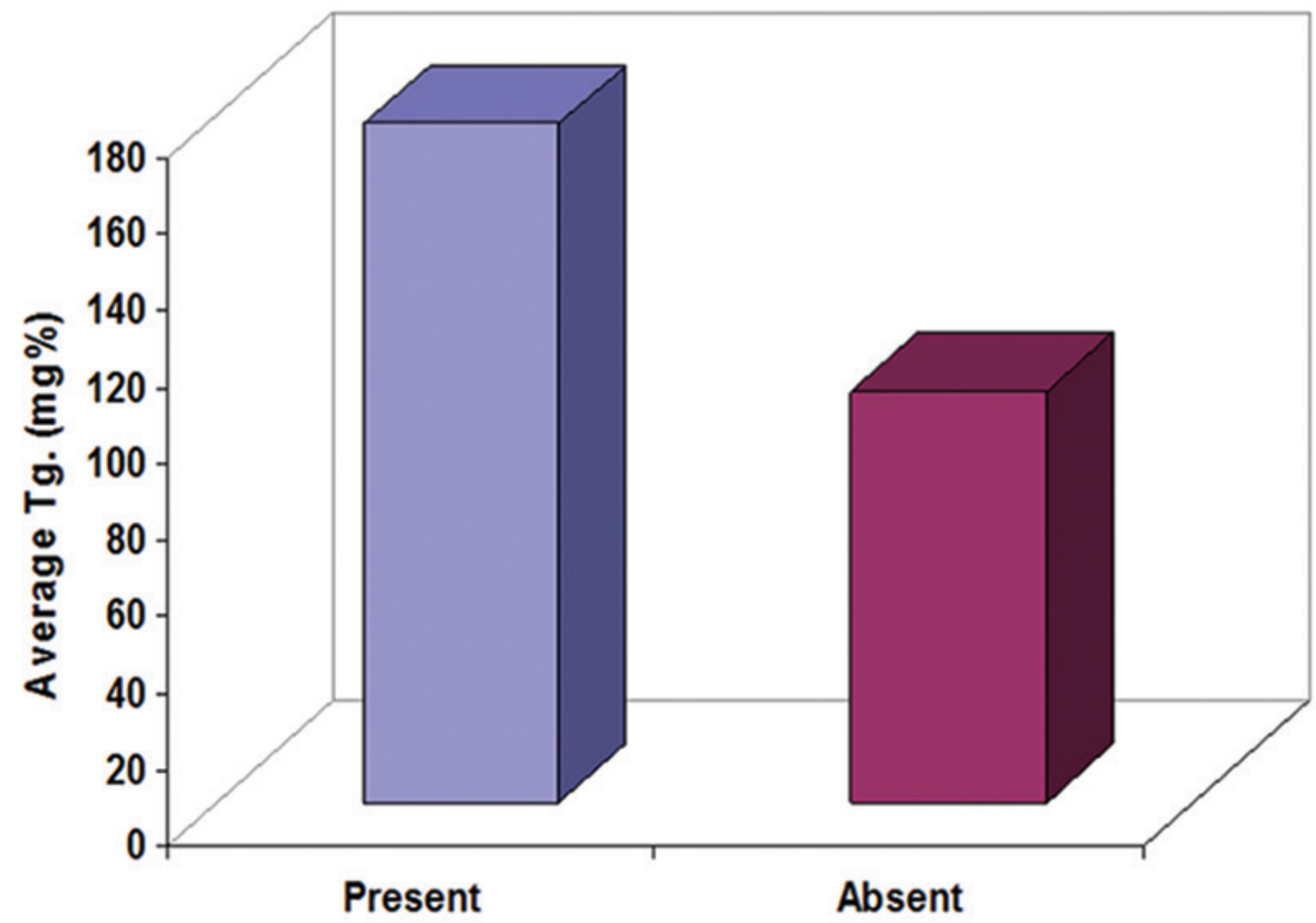

Autonomic dysfunction

-In this study, the cutoff value for normal Serum LDL-Cholesterol is taken as $<0.0001$ which is statistically significant. Hence, the correlation of autonomic dysfunction and serum LDL level in healthy postmenopausal women is proved [Figure 8 and Table 6].

Table 6:-Comparison of Sr. LDL according to autonomic dysfunction in study group

\begin{tabular}{|l|l|l|l|l|l|l|}
\hline \multirow{3}{*}{ Parameter } & \multicolumn{2}{|l|}{ Autonomic dysfunction } & \multirow{2}{*}{ Z Value } & \multirow{2}{*}{ P Value } \\
\cline { 2 - 5 } & Present (n=40) & Absent (n=20) & & \\
\cline { 2 - 5 } & Mean & SD & Mean & SD & & \\
\hline Sr. LDL (mg\%) & & & & & & \\
\hline
\end{tabular}




\section{Bar diagram showing comparison of Sr. LDL according to autonomic dysfunction in study group}

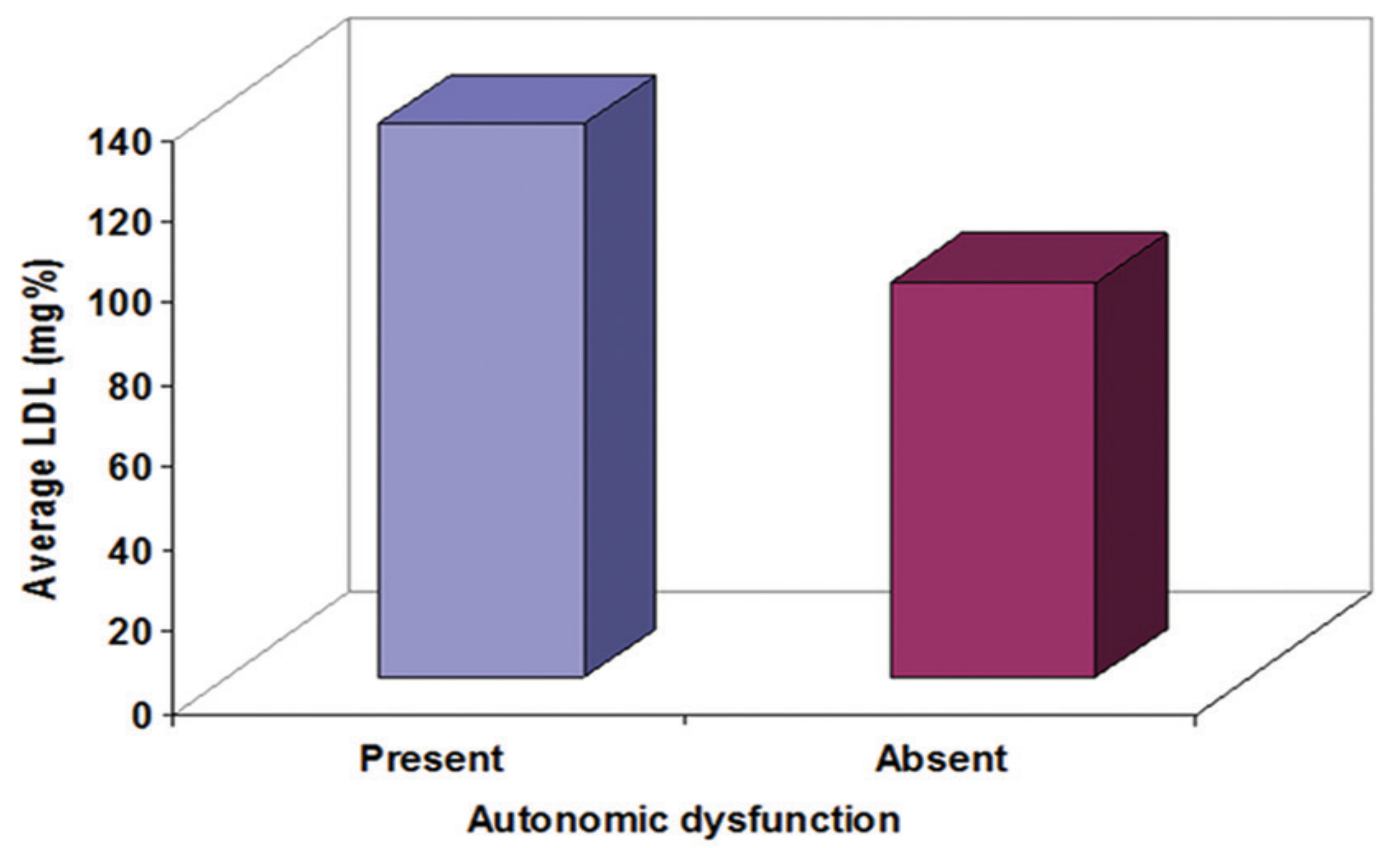

Figure 8:-Bar diagram showing comparision of serum LDL-Cholesterol according to autonomic dysfunction in study group

-In this study, the cutoff value for normal HDL-Cholesterol levels is taken as 0.05 which is not statistically significant [Figure 9 and Table 7]. 


\section{Bar diagram showing comparison of Sr. HDL according to autonomic dysfunction in study group}

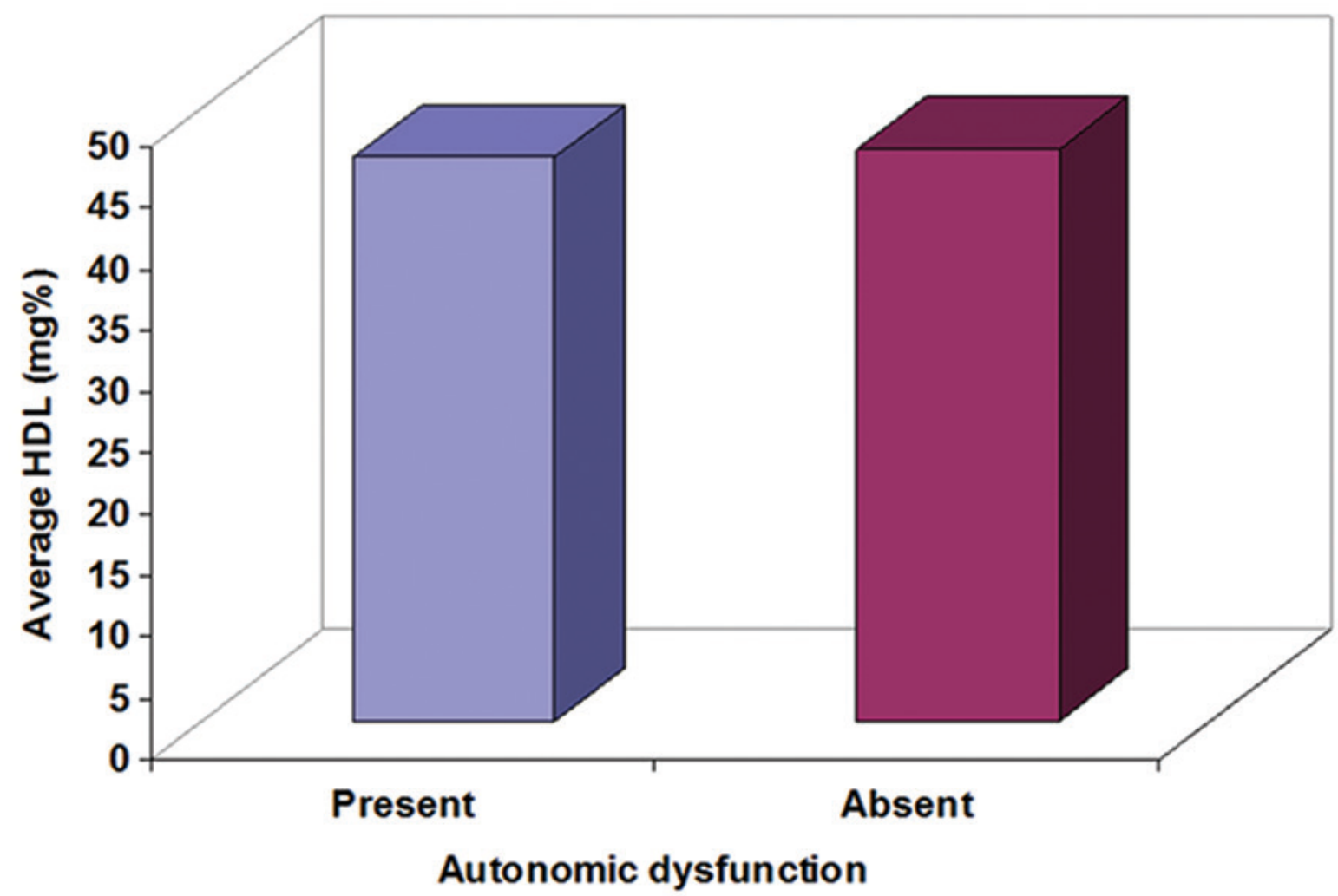

Figure 9:-Bar diagram showing comparision of serum HDL-Cholesterol according to autonomic dysfunction in study group

Table 7:-Comparison of Sr. HDL according to autonomic dysfunction in study group

\begin{tabular}{|l|l|l|l|l|l|l|}
\hline \multirow{3}{*}{ Parameter } & \multicolumn{2}{|l|}{ Autonomic dysfunction } & \multirow{2}{*}{ Z Value } & \multirow{2}{*}{ P Value } \\
\cline { 2 - 5 } & Present (n=40) & \multicolumn{2}{|l|}{ Absent (n=20) } & \\
\cline { 2 - 4 } & Mean & SD & Mean & SD & & \\
\hline Sr. HDL (mg\%) & 45.95 & 3.95 & 46.65 & 2.94 & 0.77 & $>0.05$ \\
\hline
\end{tabular}

\section{Discussion:-}

Our study was carried out in sixty healthy postmenopausal women fulfilling inclusion criteria in Dr. D. Y. Patil Hospital and Research Centre, Pimpri, Pune, from July 2012 to August 2014.

In our study, the largest group was in the age range of 55-60 years (50\%) and the females of age range of 50-55 years is $20 \%$ and females of age range of $60-65$ years is $30 \%$.

-In this study, most of the cases have the normal body mass index and normal waist-hip ratio and their comparison with autonomic dysfunction is not statistically significant, $P>0.05$. However, in the study by Kimura et al.,[12] obese patients had significantly lower autonomic functions as compared to nonobese patients.

-Out of sixty healthy postmenopausal women in this study, 41 patients have dyslipidemia - out of which 40 patients have autonomic dysfunction. 
The $P<0.0001$ is statistically significant hence proving a strong correlation between autonomic dysfunction and dyslipidemia in healthy postmenopausal women.

Our data correlate well with other studies like Virtanen et al. performed autonomic nerves system tests in healthy postmenopausal women, who were both on and off estrogen replacement therapy. Their results showed autonomic nervous function normal for age. However, in their work, the authors did observe a highly sensitive baroreflex and a strong $30 \mathrm{mmHg}$ blood pressure rise in the orthostatic test after administration of estrogen.[13]

Saeki et al. studied the difference in autonomic regulation induced by posture change between postmenopausal and young women. Their results suggested that cardiac parasympathetic tone may be reduced in older persons in comparison with young women.[14]

In the Framingham Heart Study,[15] plasma TGL is an independent predictor of coronary artery disease. This study presented with TGL level $>140 \mathrm{mg} / \mathrm{dl}$ in postmenopausal age group in 35\% of cases. [15] In the present study, $61 \%$ of healthy postmenopausal women included in the study have serum TGL level $<150 \mathrm{mg} / \mathrm{dl}$ and on comparison with autonomic dysfunction, $P<0.0001$ which is statistically significant. Hence, the correlation of autonomic dysfunction and serum TGL level in healthy postmenopausal women is proved.

Significant changes in LDL cholesterol and TC like this study were also seen in studies of Danevet al.[16] and Donchevaet al.,[17] in which hypercholesterolemia is associated with decreased 24-h heart rate variability, and decreased heart rate variability is a strong predictor of coronary heart disease.

Our study is well correlated with a recent study conducted by Chaudhuriet al.[18] results showed significant changes in values of autonomic dysfunction tests such as heart rate variability on Valsalva maneuver, deep breath test, and 30:15 R-R intervals and in values of TC, TGL, and LDL in postmenopausal women and the findings of the study indicate an association of postmenopausal altered sympathovagal activity with blood lipid concentrations and the postmenopausal women had a significantly reduced vagal index and a higher sympathetic index of heart rate variability which also support the results of study by Rosanoet al.[19]

In this study, the cutoff value for normal TC is taken as $<200 \mathrm{mg} / \mathrm{dl}$ and on comparison with autonomic dysfunction, $P<0.0001$ which is statistically significant. Hence, the correlation of autonomic dysfunction and serum cholesterol level in healthy postmenopausal women is proved.

The cutoff value for normal serum LDL cholesterol in our study is taken as $<130 \mathrm{mg} / \mathrm{dl}$ and on comparison with autonomic dysfunction, $P<0.0001$ which is statistically significant. Hence, the correlation of autonomic dysfunction and serum LDL level in healthy postmenopausal women is proved. In this study, the cutoff value for normal HDL cholesterol is taken as $<40 \mathrm{mg} / \mathrm{dl}$ and on comparison with autonomic dysfunction, $P>0.05$ which is not statistically significant.

\section{Results and Conclusion:-}

In the present study, autonomic dysfunction is found in $67 \%$ of healthy postmenopausal women. The sixty female healthy postmenopausal women included in the study, $68 \%$ has dyslipidemia.

1. In our study, there is statistically significant correlation between autonomic dysfunction and dyslipidemia in healthy postmenopausal women

2. In the healthy postmenopausal women with increased serum cholesterol, serum LDL, and serum TGLs, autonomic dysfunction is present which is statistically significant

3. There is no statistical significance is found on comparison of serum HDL cholesterol with the autonomic dysfunction in healthy postmenopausal women.

Declaration of patient consent:-

The authors certify that they have obtained all appropriate patient consent forms. In the form the patient(s) has/have given his/her/their consent for his/her/their images and other clinical information to be reported in the journal. 


\section{References:-}

1. Report of a WHO Scientific Group. Research on the menopause in the 1990s. World Health Organ Tech Rep Ser 1996;866:1-107.

2. Kalantaridou SN, Naka KK, Bechlioulis A, Makrigiannakis A, Michalis L, Chrousos GP, et al. Premature ovarian failure, endothelial dysfunction and estrogen-progesterone replacement Trends EndocrinolMetab 2006;17:101-9.

3. Naher LA, Begum N, Begum S, Ferdousi S, Ali T, Sultana M, Ali ML. The relationships of parasympathetic nerve function parameters with endogenous estrogen level in postmenopausal women. The ORION Medical Journal 2009;32:654-6.

4. Burger HG, Dudley EC, Hopper JL, Shelley JM, Green A, Smith A, et al. The endocrinology of the menopausal transition: A cross-sectional study of a population-based sample. J ClinEndocrinolMetab 1995;80:3537-45.

5. Tsuji H, Larson MG, Venditti FJ Jr., Manders ES, Evans JC, Feldman CL, et al. Impact of reduced heart rate variability on risk for cardiac events. The Framingham Heart Study. Circulation 1996;94:2850-5.

6. Ankleseria BS, Soneji RM: Risk-Benefit balance in man of menopause. In: Purandare CN, Khadilkar SS, editors. Menopause: Current Concepts; FOGSI. 1st ed. Jaypee brothers; 2004. p. 201-2.

7. Pal GK, Pal P. Autonomic function tests. Textbook of Practical Physiology. 2nd ed. Orient BlackSwan/ Universities Press; 2005. p. 296-304.

8. Ewing DJ, Clarke BF. Diagnosis and management of diabetic autonomic neuropathy. Br Med J (Clin Res Ed) 1982;285:916-8.

9. Torsvik M, Häggblom A, Eide GE, Schmutzhard E, Vetvik K, Winkler AS. Cardiovascular autonomic function tests in an African population. BMC EndocrDisord 2008;8:19.

10. Park K. Park's Textbook of Preventive and Social Medicine. Jabalpur, India: Bhanot; 2009. p. 315.

11. Kushner RF. Evaluation and management of obesity. Harrison'sPrinciples of Internal Medicine. 18th ed. Vol. 2. Ch. The NewyorkMcGrawhill Companies Inc; 2012. p. 3158-61. [742-56].

12. Kimura T, Matsumoto T, Akiyoshi M, Owa Y, Miyasaka N, Aso T, et al. Body fat and blood lipids in postmenopausal women are related to resting autonomic nervous system activity. Eur J ApplPhysiol 2006;97:542-7.

13. Virtanen I, Polo-Kantola P, Erkkola R, Polo O, Ekholm E. agement Climacteric vasomotor symptoms do not imply autonomic dysfunction. Br J ObstetGynaecol 1999;106:155-64.

14. Saeki Y, Atogami F, Hiraishi M, Furuta N, Yoshizawa T. Impairment of autonomic function induced by posture change in postmenopausal women. J Womens Health 1998;7:575-82.

15. Posner BM, Cupples LA, Miller DR, Cobb JL, Lutz KJ, D'Agostino RB. Diet, menopause, and serum cholesterol levels in women: the Framingham Study. Am Heart J 1993;125(2 Pt 1):483-9.

16. Danev S, Nikolova R, Kerekovska M, Svetoslavov S. Relationship between heart rate variability and hypercholesterolaemia. Cent Eur J Public Health 1997;5:143-6.

17. Doncheva NI, Nikolova RI, Danev SG. Overweight, dyslipoproteinemia, and heart rate variability measures. Folia Med (Plovdiv) 2003;45:8-12.

18. Chaudhuri A, Borade NG, Hazra SK. A study of heart rate variablity tests and lipid profile in postmenopausal women. J Indian Med Assoc 2012;110:228, 230-2.

19. Rosano GM, Patrizi R, Leonardo F, Ponikowski P, Collins P, Sarrel PM, et al. Effect of estrogen replacement therapy on heart rate variability and heart rate in healthy postmenopausal women. Am J Cardiol 1997;80:815-7. 